Iatsunskyi I. R., ${ }^{a b}$ Nowaczyk G, ${ }^{b}$ PavlenkoM.M. ${ }^{a}$ Fedorenko V V, ${ }^{a}$ Smyntyna V A. ${ }^{a}$

${ }^{a}$ Odessa I. I. Mechnikov National University, Department of Experimental Physics, str. Pastera 42, Odessa, Ukraine, 65023, yatsunskiy@gmail.com

${ }^{b}$ Nanobiomedical Center, Adam Mickiewicz University in Poznan, ul. Umultowska 85, Poznań, Poland, PL 61614 cnbmadm@amu.edu.pl

\title{
ONE AND TWO-PHONON RAMAN SCATTERING FROM NANOSTRUCTURED SILICON
}

Raman scattering from highly/low resistive nanostructured silicon films prepared by metal-assisted chemical etching was investigated. Raman spectrum of obtained silicon nanostructures was measured. Interpretation of observed one and two-phonon Raman peaks are presented. First-order Raman peak has a redshift and broadening. This phenomenon is analyzed in the framework of the phonon confinement model taking into account mechanical stress effects. Second-order Raman peaks were found to be shifted and broadened in comparison to those in the bulk silicon. The peak shift and broadening of two-phonon Raman scattering relates to phonon confinement and disorder. A broad Raman peak between $900-1100 \mathrm{~cm}^{-1}$ corresponds to superposition of three transverse optical phonons $\sim 2 \mathrm{TO}$ (X), 2TO (W) and 2TO (L). Influence of excitation wavelength on intensity redistribution of two-phonon Raman scattering components (2TO) is demonstrated and preliminary theoretical explanation of this observation is presented.

\section{Introduction}

Nanostructured silicon is presently of widespread interest because $\mathrm{Si}$ is an extremely promising material not only for electronics but optoelectronics, solar cells, sensors etc. Advanced nanosilicon technologies require a detailed study of obtained structures. Therefore, new methods and approaches should be performed for nanosilicon study.

Raman scattering has become a standard tool to study the silicon and nanostructured silicon for many years [1-15]. Raman-scattering studies of nanomaterials give us information about energy dispersion, structure, bonding and disorder. The analysis of nanostructures is mainly based on the phonon confinement model in which the finite crystallite size is taken into account by weighting the phonon-scattering efficiency [3-8]. Confinement effects in nanostructures lead to modifications of the electronic, optical and vibrational properties. Unfortunately, if a first-order Raman spectrum of nanocrystalline silicon has been studied extensively, the second-order Raman scattering is investigated marginally [1-3].

In the second-order Raman scattering process, two phonons of equal and opposite momentum participate and produce either line or broad continuous spectrum. Zone edge phonons, which appear only in higher-order Raman scattering, correspond to large wave vectors and are sensitive to short-range disorder. The nature of a material, such as crystalline or amorphous, can therefore be ascertained by analyzing the higher-order phonons as well. Study of second-order Raman scattering, in addition to first-order spectra, provides important information on the vibrational modes, energy structure, and morphology of nanostructured materials. Besides, second-order Raman scattering exhibits a higher sensitivity to nanoparticles size than first-order scattering [3-5].

In this paper we present the one- and two-pho- non Raman spectra of nanostructured silicon fab 
ricated by metal-assisted chemical etching. We have measured the Raman frequency shifts and line shapes at room temperature. We focused on the changes in the second-order Raman scattering. New effect dealing with second-order Raman scattering was found.

\section{Experimental procedure}

\subsection{Nanostructured siliconfabrication}

The nanostructured silicon samples were fabricated using a metal-assisted chemical etching process (MACE) [16-18]. The MACE exhibits good process controllability to generate various nanostructured silicon surface morphologies. Similar to electrochemical etching to create porous silicon, MACE acts as a localized electrochemical etching process in which local electro- deless etching occurs at the metal/silicon interface, each nanometer-sized metal particle acts as a local cathode and the silicon surface acts as an anode. The metal particles are critical in the process to promote $\mathrm{H}_{2} \mathrm{O}_{2}$ decomposition and cause electron-hole injection into the silicon surface; silicon is dissolved by $\mathrm{HF}$ to create pits or other nanostructures on the surface.

Monocrystalline p-type Si samples with resistivity of $0.005 \mathrm{Ohm} \mathrm{cm}$ (samples $A, B$ ) and with resistivity of 80 Ohm cm (samples $C, D$ ), after standard RCA cleaning, were cleaned with acetone and deionized water via ultrasonic cleaning. A thin oxide layer was formed, and the surface became hydrophilic. This oxide layer was removed by dipping the samples into a dilute HF solution. The silver particles, which act as catalysts to assist the etching of silicon, were deposited on $\mathrm{Si}$ samples by immersion in $0.23 \mathrm{M} \mathrm{HF}$ and $10^{3} \mathrm{M} \mathrm{AgNO}_{3}$ metallization aqueous solutions. The time of immersion was varied - 40 s. for samples A and sample C; and 200 s. for sample B and sample D. After the electroless metallization, the wafers were etched in aqueous solutions containing $\mathrm{HF}$ (40\%), $\mathrm{H}_{2} \mathrm{O}_{2}$ (30\%), and ultrapure $\mathrm{H}_{2} \mathrm{O}$ at ratio concentration $\mathrm{H}_{2} \mathrm{O}_{2} / \mathrm{H}_{2} \mathrm{O} / \mathrm{HF}=10 / 80 / 40$, for 30 minutes. After etching, the samples were etched in $\mathrm{HNO}_{3}$ solution to remove silver particles and then were cleaned with deionized water and blown dry with nitrogen. The etching and immersion procedures were performed at room temperature.

\subsection{Surface morphology characterization}

Structural properties of porous silicon prepared by metal-assisted chemical etching have been investigated by Scanning Electron Microscopy (SEM) - Jeol 7001TTLS and Atomic Force Microscope (Bruker company) BioScope Catalyst. AFM measurements were carried out in contact mode. Using AFM and SEM, we could characterize the shape and sizes of nanostructures, their distribution and other parameters of morphology. In order to determine mechanical stresses of obtained structures we used X-ray diffraction analysis. . X-ray diffraction (XRD) data were collected using an Empyrean diffractometer using a copper $\mathrm{X}$-ray source operating at $30 \mathrm{~mA}$ and $40 \mathrm{kV}$ providing $\mathrm{K}_{\mathrm{a}}$ radiation at a wavelength of $1.5408 \hat{\mathrm{A}}$. XRD data were collected in the range $20^{\circ}$ to $80^{\circ} 29$ with a step size of $0.013^{\circ}$.

\subsection{Raman measurement}

Raman scattering measurements were performed using a Renishaw micro-Raman spectrometer equipped with a confocal microscope (Leica). The samples were measured in backscattering geometry with a spectral resolution better than $1.0 \mathrm{~cm}^{-1}$. The incident light was not polarized; also the detection setup contained no polarization filters. The Raman scattering spectra were excited by $488 \mathrm{~nm}, 514 \mathrm{~nm}$ and $633 \mathrm{~nm}$. The beam was focused on the samples with a $50 \mathrm{x}$ microscope objective with a numerical aperture of 0.4 . The incident optical power was changed by using neutral density filters in the beam path. The minimum power for which a signal could be measured was limited by the signal to noise resolution of the detector in the spectrometer. All measurements were performed at room temperature in ambient atmosphere.

\section{Results and Discussions}

\subsection{Morphology study of nanostructured silicon}

Figs. 1 (A)-(D) are the images of scanning electron microscopy, which show the surface morphology of nanostructured silicon samples fabricated by MACE. Samples A and B have mostly the porous structure. This morphology 
shown in images indicates pores of different sizes depending on the chemical procedures. On the other hand, AFM studies of that samples show the presence of nanometer-sized pyramids (hillocks) between the macropores. These hillocks apparently correspond to Si nanocrystallites, whereas the hollows between them correspond to the narrow (nanometer) pores on the surface. The lateral dimensions of the hillocks, which were determined from AFM images as their largest linear dimensions at a base, are in the range of 15-20 $\mathrm{nm}$. The sizes of hillocks increase down to the bottom of pores. It should be noted that the actual lateral dimensions of the elements of the structure are smaller than the dimensions of the AFM images by approximately the doubled radius of the probe tip.

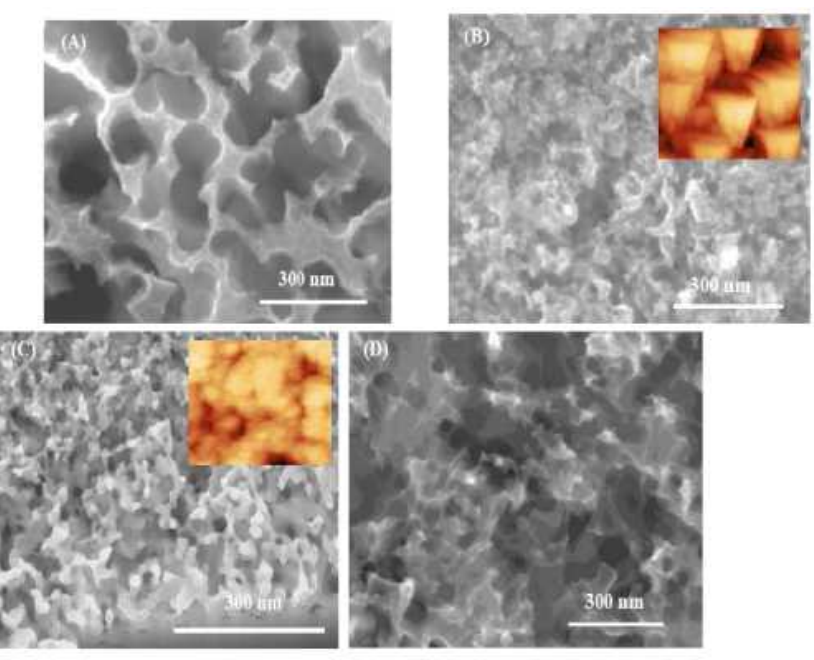

Fig. 1 SEM images of nanostructured silicon (insets are AFM images): Ag particles were deposited on Si samples by immersion in $\mathbf{0 . 2 3}$ $\mathrm{M} \mathrm{HF}$ and $10^{-3} \mathrm{M} \mathrm{AgNO}_{3}$ metallization aqueous solutions. The time of immersion was varied $-\mathbf{4 0} \mathrm{s}$. for samples (A) and sample (C); and 200 s. for sample (B) and sample (D). Etching solution contained $\mathrm{HF}(40 \%), \mathrm{H}_{2} \mathrm{O}_{2}(30 \%)$, and ultrapure $\mathrm{H}_{2} \mathrm{O}$ at ratio concentration $-\mathrm{H}_{2} \mathrm{O}_{2} /$ $\mathrm{H}_{2} \mathrm{O} / \mathrm{HF}=10 / 80 / 40$, for 30 minutes.

Samples C and D have mostly the "coral-like" structure similar to nanowires with different orientation. Wires have approximate dimensions lying in the range of 10-25 nm. AFM shows mostly the cauliflower-like structure. This morphology shown in 2D images indicates several particles (granules) embedded in each grain (Fig.l(c) inset). However, the shapes, as well as arrangement of the grains, were found to be different.

All these results confirm that different morphologies can be produced by varying either the dopant level and, of course, the type of etchant and deposition solution.

\subsection{Raman scattering investigations of nanostructured} silicon

Under normal conditions (standard pressure and temperature), silicon crystallizes in a diamond lattice structure, which belongs to the $\mathrm{O}_{\mathrm{n}}{ }^{7}$ space group. The diamond structure of silicon allows only one first-order Raman active phonon of symmetry $\Gamma_{25}$ located at the Brillouin zone (BZ) centre corresponding to a phonon wave vector $520.0 \pm 1.0 \mathrm{~cm}^{-1}$ with the full width at half maximum (FWHM) - $3.5 \mathrm{~cm}^{-1}$. In order to interpret other Raman peaks, the Table .1 shows more important phonon frequencies of silicon [1-15].

Table 1

Silicon Phonon Frequencies

\begin{tabular}{|c|c|}
\hline Physical property & Phonon frequencies $\left.\mathbf{( c m}^{-1}\right)$ \\
\hline LTO $(\Gamma)$ & $517-519$ \\
\hline TA $(X 3)$ & $149-151$ \\
\hline LAO (X1) & $410-411$ \\
\hline TO (X4) & $460-464$ \\
\hline TA (L3) & $113-115$ \\
\hline TA ( $\Sigma)$ & 230 \\
\hline LA (L2) & $377-379$ \\
\hline LO (L1) & 420 \\
\hline TO (L3) & 490 \\
\hline TO (W) & 470 \\
\hline
\end{tabular}

Raman scattering spectra of samples 1-4 are shown in Fig.2, for an incident laser power of $10 \mathrm{~mW}$. For all samples one can notice the quite similar Raman spectrum. High peak at 518-519 cm with the FWHM of 8.5-15 $\mathrm{cm}^{-1}$ can be seen in the Raman spectrum of nanostructured $\mathrm{Si}$. The intensity of the first-order scattering which is due 
to the optical phonons (TO, LO) at the center $\Gamma$ point of the $\mathrm{BZ}$, as was mentioned above, is much stronger in comparison with that from the initial $\mathrm{Si}$ wafer. In comparison with the first-order optical phonon peak of c-Si, the corresponding Raman peak of nano-Si has very small frequency down-shifted, its linewidth broadened and its line shape becomes asymmetric with a little tail on the low-energy side extending to $470-480 \mathrm{~cm}^{-1}$ for all samples what indicate on partial amorphous- like structure. The first-order spectrum from bulk Si single crystal represents scattering by optical phonons with quasimomentum $\mathbf{q}=0$ because of its conservation in an infinite lattice. Studies of the morphology and structure of nano - Si by SEM/ AFM has revealed the presence of nanostructures with dimensions on a nanometer scale (Fig. 1). The limitation of the translation symmetry leads to relaxation of this selection rule, and phonons with quasimomentum out of the region around the $\Gamma$ point determined by the size of the crystallite can contribute to the scattering. Due to the decrease in the frequency of optical phonons with $\mathbf{q}$ in the vicinity of the BZ center, the Raman line of a spectrum from nanocrystalline material is shifted to lower energies and broadened. But comparing our experimental data with references one should conclude that there are additional reasons of the red-shifting and broadening. It is well known that effects of sample heating caused by laser radiation, compressive stress and defects give rise to a frequency shift of the Raman peak [2, 5, 9]. Therefore, it is necessary to take into account the relative contributions of different mechanisms to the Raman shift and broadening if one need to obtain more precise results for peak line shape.

Khorasaninejad et al. showed that the main reason of red-shifting, but not the peak broadening, is heating effect [22]. They also showed that if confinement effects take place the red-shifting would be approximately 1-2 $\mathrm{cm}^{-1}$ which corresponds to our case. Regarding the impact of compressive stress and defects we can estimate it taking into account the following equations [3]

$$
\frac{\delta \omega}{\omega}=-3 \gamma \frac{a_{k \gamma}-a_{01}}{a_{0}}
$$

where $\delta \omega \delta)$ is the peak width, $\alpha_{P S} \alpha_{\beta}$ is the lattice constant of porous silicon (PS) nanostructures, and $\gamma \approx 7 \sim 1-0$ is the Gruneisen constant. The derived values of strain $\frac{\alpha_{P S}-\alpha_{0}}{\alpha_{0}} \quad \frac{\alpha_{B}-\alpha_{0}}{\alpha_{0}}$ can be estimated from $\mathrm{X}$-Ray diffrâction Analysis. We have obtained this value and it turned out to be an order of $10^{-3}$ for different samples.

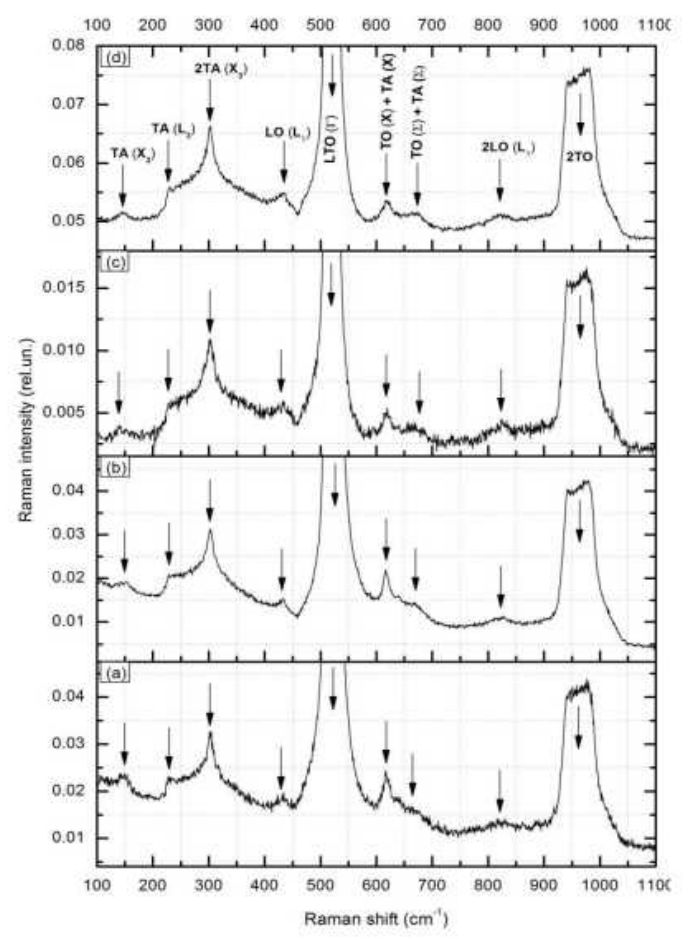

Fig. 2 Normalized Raman spectrum of Si nanostructures taken with a $514 \mathrm{~nm}$ laser. (A) - (D) - sample, respectively.

Campbell and Fauchet [23] developed a quantitative model that calculates the Raman spectrum of PS as depending on the size $L$ and on the shape of the porous silicon crystallites. If PS is modeled as an assembly of quantum wires, the phonon confinement is assumed to be two dimensional, while if the PS is modeled as an assembly of quantum dots, the confinement is three dimensional. The Raman spectrum is given by:

$$
I(\omega) \cong \int_{B Z} \frac{d^{3} q|C(0, q)|^{2}}{(\omega-\omega(q))^{2}-\left(\frac{\Gamma_{0}}{2}\right)^{2}}
$$


where

$$
|C(0, q)|^{2}=\exp \left(-\frac{q^{2} L^{2}}{16 \pi^{2}}\right)
$$

The first-order Raman spectrum $I(\propto)$ is thus given by:

$I(\omega) \cong \int_{B Z}^{4 \pi q^{2} \exp \left(-\frac{q^{2} L^{2}}{16 \pi^{2}}\right) d^{3} q}$,

where $\Gamma_{0}$ is the natural linewidth for $\mathrm{c}-\mathrm{Si}$ at room temperature but we should add to this value linewidth corresponding to compressive stress \& and ${ }^{\circledR}(q)$ is the dispersion relation for optcal pho- nons in c-Si. This expression can be taken as [23]:

$$
\omega=\omega_{0}-120\left(\frac{q}{q_{0}}\right)^{2} .
$$

Here, ( $\dot{U}_{0}$ is the position of the c-Si Raman peak. By specifying the size of the silicon nanocrystallites, from eqs. (4) and (5) the relation between the peak shift and the linewidth in the framework of the phonon confinement model can be determined. Taking into account the impact of compressive stress and confinement effects we reconstructed the Raman spectrum. The results of calculations are presented in Fig. 3. It can be noticed that values of nanocrystallites sizes obtained from calculations are smaller than from SEM. That can be explained by the limited resolution of the electron microscope.

In contrast to c-Si, one can see the first-order scattering from acoustical phonons at $150 \mathrm{~cm}^{-1}$ and optical phonon at $430 \mathrm{~cm}^{-1}$. These peaks correspond to TA phonon at $X$ critical points - TA (X) and to LO phonon at L critical points -LO (L), respectively (Table 1). The last peak suggests that nanostructured silicon in some extent is in amorphous form $[7,15]$.

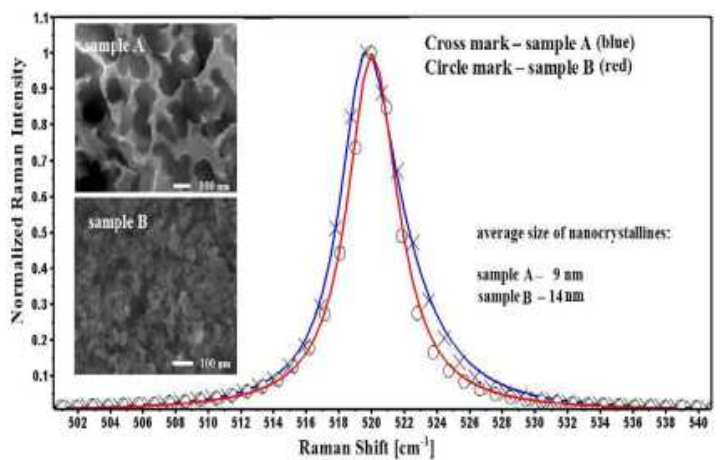
Fig. 3 Experimental and calculated curves of
nanostructured silicon surface (sample A, B).

A strong enhancement of multiphonon features occurs for nanostructured silicon. The second order spectrum is much weaker than the first-order peak LTO ( $\Gamma)$ with features ranging from $1001100 \mathrm{~cm}^{-1}$. The second-order spectrum of transverse 2TA acoustical phonons is clearly observed near $300 \mathrm{~cm}^{-1}$. Some authors suggest this peak is corresponding to LA modes $[11,13]$ but there is not accurately confirmation of this fact. Probably we observe the superposition of transverse and longitudinal acoustic modes. Comparing the peak position with the values in the Table 1, we can assume that this peak corresponds to TA overtones at $X$ critical points - 2TA (X). We can also observed few little two-phonon peaks - 2TA (L) at $230 \mathrm{~cm}^{-1}$ and 2LO (L) at $830 \mathrm{~cm}^{-1}$. Some authors explain the 2LO (L) by some kind of disorder but it still is open question. In addition, we also found two obvious peaks of $\mathrm{Si}$ nanocrystallines at 630 and $670 \mathrm{~cm}^{-1}$ which can be ascribed to the quantum confinement effect of Si. These peaks are composed of contributions from combinations and also from overtones of transverse optical and acoustical modes of different critical points. The peak at $630 \mathrm{~cm}^{-1}$ probably corresponds to the combination TO (X) +TA (X) modes and weaker peak corresponds to TO $(\Sigma)+\mathrm{TA}(\Sigma)[5,9]$. Probably, longitudinal modes are also taking part in these combinations as indicated in some publications [4, 11]. And finally, there is a broad peak between $900-1100 \mathrm{~cm}^{-1}$ which is from the scattering of few transverse optical phonons 2TO phonons. A more detailed discussion of this peak will be further. 
Since fundamental phonon modes are shifted and broadened, the second-order modes of nanostructured silicon are also shifted and broadened. In addition to the peaks which can be attributed to the scattering from crystalline material, all spectra of our nanostructured silicon samples, although to different extents, exhibit broadband.

\subsection{Wavelengths effect of two-phonon Raman} scattering

For second-order scattering, the two phonons involved must have equal but opposite wave vector in order to fulfill momentum conservation. Therefore, the strongest scattered signal is due to phonons where the density of states (DOS) is highest [19]. The intensity of the second order Raman signal strongly depends on the scattering geometry due to symmetry reasons. Our results for second-order Raman scattering are shown in Fig.4. One can see the Raman spectrum of sample A. The laser power for different wavelengths had approximately the same values less than $10 \mathrm{~mW}$ to prevent heating effects. We can see a broad peak between 900$1100 \mathrm{~cm}^{-1}$ which is from the scattering of few transverse optical phonons $2 \mathrm{TO}$ phonons for different wavelength of the excitation light. To date, there is no consensus about the origin of the broad peak. Some authors argue that this peak is formed by the superposition of two or more optical modes [1-5, 19-21]. It can be seen that shape line has a kind of complexity. The Raman peak was split onto separate peaks. The peaks, located at 930940, 950-960 and 980-985 $\mathrm{cm}^{-1}$ have been found. As discussed above, the scattering in second-order reflects the phonon DOS. For bulk silicon, the DOS features few strong singularities due to TO phonon at the X-point, the $\mathrm{W}$-point and the L-point. The shoulder at 930-940 $\mathrm{cm}^{-1}$, which is identified as two-TO-phonon overtone at zone- edge point $\mathrm{X}$, emerges at $930 \mathrm{~cm}^{-1}-2 \mathrm{TO}(\mathrm{X})$. The peak at $945-955 \mathrm{~cm}^{-1}$, which is identified as two-TOphonon overtone at zone-edge point $\mathrm{W}$, emerges at 940 $\mathrm{cm}^{-1}$ - 2TO (W). Furthermore, the peak at $980 \mathrm{~cm}^{-1}$ corresponding to 2TO-phonon overtone scattering from the critical point $\mathrm{L}$, appears at $980 \mathrm{~cm}^{-1}-2 \mathrm{TO}(\mathrm{L})$. It was noticed that the $2 \mathrm{TO}$ peaks narrow as the size of the nanostructures become larger. It is clear from these results that the 2TO band is affected by confinement effects and shifts towards lower frequency and becomes broader as the dimension of the nanocrystals decreases.

Exploring the patterns of change in this peak, depending on the wavelength of the excitation light $\left(k_{\text {ex }}\right)$ we found an interesting effect. Changing the $k_{\text {exc }}$ leads to an intensity redistribution of Raman scattering components. One can notice that for $\kappa=488 \mathrm{~nm}$ and $X$ $=514 \underset{\text { exc }}{\mathrm{nm}}$ the peaks of $2 \mathrm{TO}$

(L) and 2TO (W) prevail over the 2TO (X) mode. For the $k_{\text {exc }}=633 \mathrm{~nm} 2 \mathrm{TO}(\mathrm{X})$ phonon overtone comes maximum and the left shoulder of the broad peak becomes much higher than right shoulder. We compared this result with other publications [1-5, 9-10, 13, 15-16]. Indeed, in other publication one can notice, although to different extents, the same effect. Unfortunately, no one paid attention to this experimental observation.

In order to explain this effect we considered following assumptions: increasing in the intensity of the second-order Raman scattering depends on Raman tensor and effective Raman scattering cross-section. On the other hand, the Raman tensor depends on the probability of interband optical transitions [20-21]. Photons with energies corresponding to the absorption edge for a certain zone- edge point of BZ should have a higher probability of optical transitions and thereby the intensity of Raman peak for certain zone-edge point would increase or decrease its value.

The intensity of second-order spectra, $I_{2}(\omega)$, is related to that of first-order scattering, $\mathrm{I}_{\mathrm{j}}(\mathrm{ro})$, through [21]

$I_{2}(\omega) \approx I_{1}(\omega) f\left(\frac{\hbar \omega_{i}}{\hbar \omega_{g}}\right)$

where $\hbar \omega_{i}$ energy of laser photon, $h \omega_{g}$ energy equal to band gap width in material. The function

$f\left(\frac{\hbar \omega_{i}}{\hbar \omega_{g}}\right)$

depends in a fairly complex way on the

ratio $\left(\frac{\hbar \omega_{i}}{\hbar \omega_{g}}\right)$ If $\hbar \omega_{i}$ is close $h \omega_{g}$ to , the inten-

sity of second-order Raman scattering becomes 
resonantly enhanced. The function describing the dependence of the second-order Raman scattering intensity on the ratio of laser beam energy to band gap width can be written as [21]

$$
f\left(\frac{\hbar \omega_{i}}{\hbar \omega_{g}}\right) \approx\left[\left(1-f\left(\frac{\hbar \omega_{i}}{\hbar \omega_{g}}\right)^{-1.5}+c o n s t\right]^{2} .\right.
$$

It is well known, that the band gap energy increasing with the decreasing of nanostructures size and it results in a growth of $f\left(\frac{\hbar \omega_{i}}{\hbar \omega_{g}}\right)$ function.

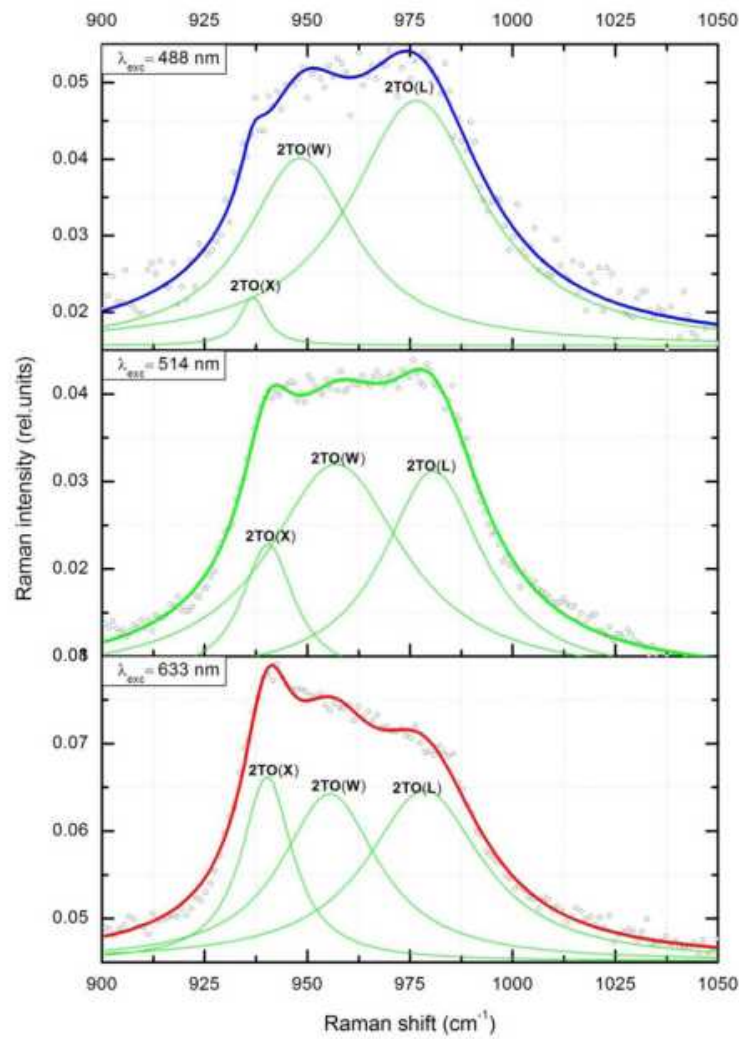

Fig. 4 Normalized Raman two-phonon scattering for three different laser wavelengths for sample A. The calculated separate secondorder modes are indicated by solid green line curve and the experimental data are plotted as colored bold line.

Thus, calculation of second-order Raman spectra intensity allows one to estimate the optical energy gap. As far as the intensity of $2 \mathrm{TO}$ is concerned, estimated calculations shows that if we use red laser instead of blue one the intensity of 2TO (X) peak should increase the intensity approximately in 2.5 times. On the other hand, for peaks (2TO (L) and 2TO (W)), their intensities should increase approximately in 1.3-1.5 times, that we observed in the experiment. However, the present explanations are tentative, and require further theoretical proof.

\section{Conclusions}

One- and two-phonon Raman scattering characteristics of nanostructured silicon fabricated by metalassisted chemical etching were investigated and the results are summarized. First-order Raman peak has a small redshift and broadening compared with bulk silicon as predicted by the phenomenological phonon confinement effect for nanostructures. In addition to the fundamental phonon modes, overtone and combinations of modes were also observed and analyzed. Secondorder Raman peaks were found to be shifted and broadened in comparison to those in the bulk silicon. A broad peak between 900-1100 $\mathrm{cm}^{-1}$ corresponds to superposition of three transverse optical phonons $\sim 2 \mathrm{TO}$ $(\mathrm{X}), 2 \mathrm{TO}(\mathrm{W})$ and $2 \mathrm{TO}(\mathrm{L})$. It was observed the anomalous behavior of the $2 \mathrm{TO}$ peaks depending on the wavelength of the excitation light. Our findings are important for characterizing of nanostructures by Raman scattering.

\section{References}

1. Rong-ping Wang, Guang-wen Zhou, Yulong Liu, Shao-hua Pan, Hong-zhou Zhang, Da-peng Yu, and Ze Zhang, "Raman spectral study of silicon nanowires: High-order scattering and phonon confinement effects", Phys. Rev. B 61(24), 16827-16832 (2000).

2. Puspashree Mishra, and K. P. Jain, "Firstand second-order Raman scattering in nanocrystalline silicon”, Phys. Rev. B 64(7), 073304-073308 (2001).

3. S. Piscanec, M. Cantoro, A. C. Ferrari, J. A. Zapien, Y. Lifshitz, S. T. Lee, S. Hofmann, and J. Robertson, "Raman Spectrum of silicon nanowires”, Phys. 
Rev. B 68(24), 241312-241316 (2003).

4. N. Korsunska, B. Bulakh, B. Jumayev, L. Khomenkova,V. Yukhymchuk, and T. Torchynska, "Raman scattering characterization of macro- and nanoporous silicon”, Applied Surface Science 243, 30-35 (2005).

5. Cedrik Meiera, Stephan Lu, Vasyl G. Kravets, Hermann Nienhaus, Axel Lorke,and Hartmut Wiggers, "Raman properties of silicon nanoparticles”, PhysicaE 32, 155-158 (2006).

6. S.K. Mohanta, R.K. Soni, S. Tripathy, C.B. Soh, S.J. Chua, and D. Kanjilal, "Raman scattering from nanopatterned silicon surface prepared by low-energy $\mathrm{Ar}+\mathrm{Ar}+$-ion irradiation”, Physica E 35, 42-47 (2006).

7. Wensheng Wei, "One- and two-phonon Raman scattering from hydrogenated nanocrystalline silicon films”, Vacuum 81, 857-865 (2007).

8. Wensheng Wei, Gangyi Xu, Jinliang Wang, and Tianmin Wang, "Raman spectra of intrinsic and doped hydrogenated nanocrystalline silicon films”, Vacuum 81, 656-662 (2007).

9. Chil-Chyuan Kuo, "Micro-Raman spectroscopy characterization of polycrystalline silicon films fabricated by excimer laser crystallization”, Optics and Lasers in Engineering 47,612-616 (2009).

10. Dorra Abidi, Bernard Jusserand, and JeanLouis Fave, "Raman scattering studies of heavily doped microcrystalline porous silicon and porous silicon freestanding membranes", Phys. Rev. B 82(7), 075210-075221 (2010).

11.

Y. Duan, J. F. Kong, and

W. Z. Shen, "Raman investigation of silicon nanocrystals: quantum confinement and laser-induced thermal effects”, J. Raman Spectrosc. 43(6), 756-760 (2012).

12. M. Khorasaninejad, J Walia, and S Saini, "Enhanced first-order Raman scattering from arrays of vertical silicon nanowires”, Nanotechnology 23, 275706- 275713 (2012).
13. Suk-Kyu Ryu, Qiu Zhao, Michael Hecker, Ho-Young Son, and Kwang- Yoo Byun, "Micro-Raman spectroscopy and analysis of near-surface stresses in silicon around through-silicon vias for three-dimensional interconnects”, J. Appl. Phys. 111, 063513063521 (2012).

14. M. Khorasaninejad, M. M. Adachi, J. Walia, K. S. Karim, and S. Saini, "Raman spectroscopy of core/shell silicon nanowires grown on different substrates", Phys. Status Solidi A 210(2), 373-377 (2013).

15. Narasimha Rao Mavilla, Chetan Singh Solanki,and Juzer Vasi, "Raman spectroscopy of silicon-nanocrystals fabricated by inductively coupled plasma chemical vapor deposition” PhysicaE 52, 5964 (2013).

16. Z. Huang, N. Geyer, P. Werner, J. De Boor, and U.Gosele, "Metal-assisted chemical etching of silicon: A review”, Advanced Materials 23(2), 285-308 (2011).

17. W. K. Kolasinski, "Silicon nanostructures from electroless electrochemical etching”, Current Opinion in Solid State \&Materials Science 9, 73-83 (2005).

18. C. Chartier, S. Bastide, and C. Levy, "Metal-assisted chemical etching of silicon in $\mathrm{HF}-\mathrm{H}_{2} \mathrm{O}_{2}$ ”, Electrochimica Acta 53(17), 5509-5516 (2008).

19. A Valentin, J Sée, S Galdin-Retailleau, and $\mathrm{P}$ Dollfus, "Phonon dispersion in silicon nanocrystals”, Journal of Physics: Conference Series 92, 012048012052 (2007).

20. M. Aouissi, I. Hamdi, and N. Meskini, "Phonon spectra of diamond, Si, Ge, and aSn: Calculations with real-space interatomic force constants”, Phys. Rev. B 74(5), 054302054312 (2006).

21. R. Loudon, “The Raman effect in crystals”, Adv. Phys. 50(7), 813-864 (2001).

This article has been received within 2014 
I. R. Iatsunskyi, G. Nowaczyk,M.M.Pavlenko, V V Fedorenko, V A. Smyntyna

\title{
ONE AND TWO-PHONON RAMAN SCATTERING FROM NANOSTRUCTURED SILICON
}

\begin{abstract}
Raman scattering from highly/low resistive nanostructured silicon films prepared by metal-assisted chemical etching was investigated. Raman spectrum of obtained silicon nanostructures was measured. Interpretation of observed one and two-phonon Raman peaks are presented. First-order Raman peak has a redshift and broadening. This phenomenon is analyzed in the framework of the phonon confinement model taking into account mechanical stress effects. Second-order Raman peaks were found to be shifted and broadened in comparison to those in the bulk silicon. The peak shift and broadening of two-phonon Raman scattering relates to phonon confinement and disorder. A broad Raman peak between $900-1100 \mathrm{~cm}^{-1}$ corresponds to superposition of three transverse optical phonons 2TO (X), 2TO (W) and 2TO (L). Influence of excitation wavelength on intensity redistribution of two-phonon Raman scattering components (2TO) is demonstrated and preliminary theoretical explanation of this observation is presented.
\end{abstract}

Key words: porous silicon, Raman scattering, metal-assisted chemical etching.

УДК 621.794: 546.48: 539.51

И. Р. Яиунский, Г. Новачик, Н. Н. Павленко, В. В. Федоренко, В. А. Смынтыниа

\section{ОДНО И ДВУХФОНОННОЕ РАМАНОВСКОЕ РАССЕЯНИЕ НАНОСТРУКТУРИРОВАННОГО КРЕМНИЯ}

\section{Резюме}

В работе представлено исследование комбинационного рассеяния (КРС) наноструктуриро- ванного кремния полученного методом химического неэлектролитического травления. Представлена интерпретация наблюдаемых одно и двухфононных пиков КРС. Было выявлено, что пики КРС первого и второго порядка смещаются и уширяются относительно пика объемного кремния. Данное явление анализируется в рамках фононного конфайнмента с учетом механических напряжений. Широкий пик КРС второго порядка в области 900-1100 см-1 соответствует суперпозиции трех поперечных оптических фононов $\sim 2 \mathrm{TO}(\mathrm{X}), 2 \mathrm{TO}$ (W) и $2 \mathrm{TO}(\mathrm{L})$.

Ключевые слова: пористый кремний, Рамановское рассеяние, неэлектролитическое травление. 
I. Р Яиунсъкий, Г. Новачик,М.М.Павленко, В. В. Федоренко, В. А. Сминтина

\section{ОДНО ТА ДФОХФОНОНЕ РАМАНІВСЬКЕ РОЗСІЯННЯ НАНОСТРУКТУРОВАНОГО КРЕМНІЮ}

\section{Резюме}

У роботі представлено дослідження комбінаційного розсіяння (КРС) наноструктурованого кремнію отриманого методом хімічного неелектролітіческіх травлення. Представлена інтерпретація спостережуваних одне і двухфононних піків КРС. Було виявлено, що піки КРС першого і другого порядку зміщуються і розширюються щодо піка об'ємного кремнію. Дане явище аналізується в рамках фононного конфайнмента $з$ урахуванням механічних напружень. Широкий пік ВРХ другого порядку в області 9001100 см-1 відповідає суперпозиції трьох поперечних оптичних фононів 2TO (X), 2TO (W) і 2 TO (L).

Ключові слова: поруватий кремній, Раманівське розсіяння, неелектролітичне травлення. 